\title{
A cost-effective and eco-friendly treatment technology to remove realistic levels of mercury by means of the unmodified rice husk
}

\author{
L. S. Rocha ${ }^{1}$, C. B. Lopes ${ }^{2}$, A. C. Duarte ${ }^{3}$ and E. Pereira ${ }^{4}$ \\ ${ }^{1}$ Department of Chemistry/CESAM, University of Aveiro, 3810-193 Aveiro, Portugal, lrocha@ua.pt \\ ${ }^{2}$ Department of Chemistry/CESAM, University of Aveiro, 3810-193 Aveiro, Portugal, claudia.b.lopes@ua.pt \\ ${ }^{3}$ Department of Chemistry/CESAM, University of Aveiro, 3810-193 Aveiro, Portugal, aduarte@ua.pt \\ ${ }^{4}$ Department of Chemistry/CESAM, University of Aveiro, 3810-193 Aveiro, Portugal, eduper@ua.pt
}

\begin{abstract}
In the present work the removal of mercury from aqueous solutions media and for realistic concentrations of this metal was evaluated, by using an inexpensive and highly available agricultural waste, rice husk. An economical method was developed based on the use of the natural/unmodified form of rice husk and on the amount of material required, which was minimized to produce the lowest amount of biological slurry. In order to study the kinetics of the process, batch stirred experiments were performed for initial concentrations of $\mathrm{Hg}^{2+}$ of: $50 \mu \mathrm{g} \mathrm{L}^{-1}$, representing the actual maximum value for $\mathrm{Hg}$ discharges from industrial sectors, and $500 \mu \mathrm{g} \mathrm{L}^{-1}$, to simulate a situation of an accidental spill. The kinetic curves were described by a rapid removal of $\mathrm{Hg}^{2+}$ by rice husk, in the first hours of contact, followed by a slower removal of $\mathrm{Hg}^{2+}$, until it reaches equilibrium. The removal of $\mathrm{Hg}^{2+}$ using a rice husk dose of $0.50 \mathrm{~g} \mathrm{~L}^{-1}$ was $c a .83 \%$ for an initial concentration of $50 \mu \mathrm{g} \mathrm{L}-1$ and $92 \%$ for $500 \mu \mathrm{g} \mathrm{L}^{-1}$. Furthermore, the results show that is possible the reuse the rice husk in additional cleaning treatments, maintaining the efficiency of the removal process.
\end{abstract}

Key words: Mercury; Rice husk; Remediation; Contaminated waters.

\section{Introduction}

Mercury $(\mathrm{Hg})$ ranks among the most harmful metals, due to its toxicity, high volatility and its persistent character in the environment and biota. In the last two decades, efficient and cost-effective approaches have been developed, to remove $\mathrm{Hg}^{2+}$ and other metal ions from waters, based on the use of non-conventional sorbents (Srivastava et al., 2010).

Rice husk is a by-product of rice processing and is considered a waste disposal problem. Although some studies can be found in the literature, related with the application of this sorbent in the removal of $\mathrm{Hg}^{2+}$ from waters, most of them uses very high concentrations of this metal, that do not reflect the contamination problems found in the environment (Tiwari et al., 1995; Khalid et al., 1999; Feng et al., 2004; El-Said et al., 2010).

The present work explores the sorption capacity of rice husk to remove $\mathrm{Hg}^{2+}$ from aqueous media, considering three fundamental aspects: i) minimize the cost of the agricultural waste by using its natural/unmodified form; ii) using realistic mercury concentrations and possible to be found in the environment; iii) minimize the concentration of sorbent used, in order to decrease the amount of rice husk residue produced, after the application of this cleaning technology. In order to achieve this, the effect of the contact time, the initial $\mathrm{Hg}^{2+}$ concentration, the sorbent dose and the possibility to reuse the material for further treatments, were evaluated.

\section{Materials and Methods}

The rice husk was kindly supplied by Álvaro Alves Borges Lda. Industries from Figueira da Foz, Portugal. Prior to its use, a simple and low-cost treatment was applied: 1) washing with distilled water, 2) drying at $60^{\circ} \mathrm{C}, 3$ ) triturating with a coffee mill and 4) sieving to obtain a fraction with particles size $\leq 500 \mu \mathrm{m}$ (Fig. 1).

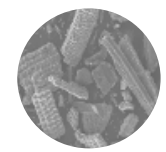

Fig. 1. SEM image of rice husk material obtained for a magnification of $50 \times$.

Sorption kinetic experiments were performed in batch procedures at room temperature $\left(21 \pm 1^{\circ} \mathrm{C}\right)$, by contact of a 
certain amount of the unmodified rice husk with a known concentration of $\mathrm{Hg}^{2+}$ solution $\left(C_{0} \mathrm{Hg}^{2+}\right)$. Volumetric flasks of $2 \mathrm{~L}$ were used and agitation conditions (1400 $\mathrm{rpm})$ were kept in the experimental trial. Aliquots were collected at increasing times $(t)$, filtrated with a $0.45 \mu \mathrm{m}$ Millipore membrane and acidified with nitric acid to $\mathrm{pH}<2$. The experiment was stopped when the concentration of $\mathrm{Hg}^{2+}$ in solution remaining constant (situation of equilibrium). Mercury samples were analysed by could vapour atomic fluorescence spectroscopy (CV-AFS), on a PSA cold vapour generator, model 10.003, associated with a Merlin PSA detector, model 10.023 and using $\mathrm{SnCl}_{2}$ as reducing agent. All experiments were conducted at room temperature and at $\mathrm{pH}$ ca. 6.0. Table 1 summarize the $C_{0 \mathrm{Hg}}{ }^{2+}$ and rice husk dose (mass of sorbent, $m$, per volume of solution, $V$ ) used in this work.

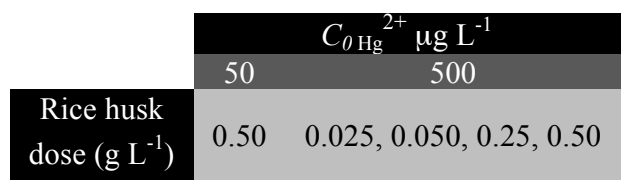

Table 1. Experimental conditions.

\section{Results and Discussion}

\section{Effect of initial $\mathrm{Hg}^{2+}$ concentration}

The efficiency of the rice husk sorbent (dose of $0.50 \mathrm{~g} \mathrm{~L}^{-1}$ ) to remove $\mathrm{Hg}^{2+}$ from solution was evaluated through a kinetic study. Two initial concentrations of $\mathrm{Hg}^{2+}$ were used: $50 \mu \mathrm{g} \mathrm{L}^{-1}$, representing the actual maximum value for $\mathrm{Hg}$ discharges from industrial sectors, and $500 \mu \mathrm{g} \mathrm{L}^{-1}$, to simulate a situation of an accidental spill.
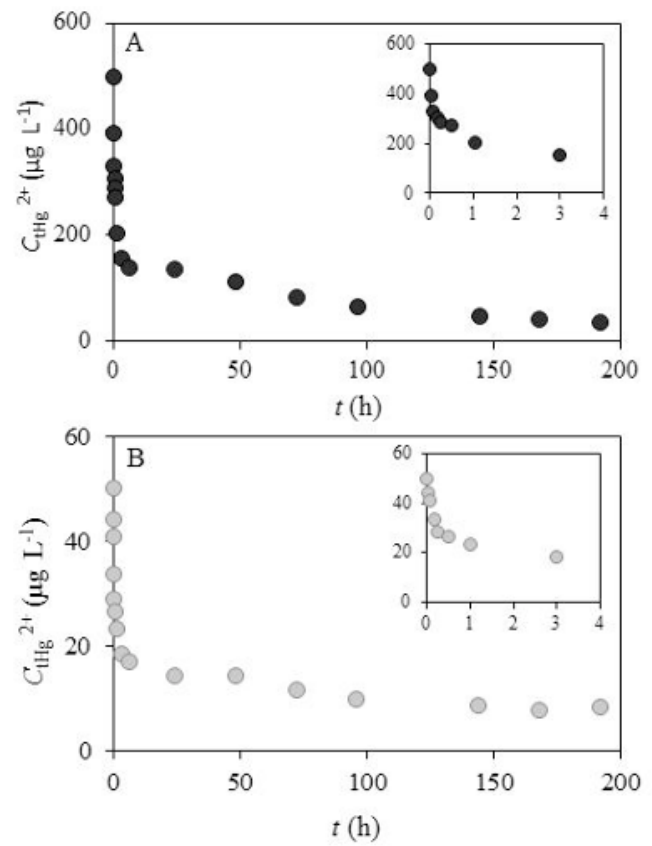

Fig. 2 Values of the concentration of $\mathrm{Hg}^{2+}$ in solution $(C$ $\left.{ }_{\mathrm{Hg}}^{2+}, \mu \mathrm{g} \mathrm{L}^{-1}\right)$ with time $(t, \mathrm{~h})$ for a $\mathrm{C}_{0 \mathrm{Hg}}{ }^{2+}$ of: (A) $500 \mu \mathrm{g}$ $\mathrm{L}^{-1}$ and (B) $50 \mu \mathrm{g} \mathrm{L}^{-1}$.
The kinetic curves (Fig. 2) show that the removal of $\mathrm{Hg}^{2+}$ by rice husk occurred in a multi stage process, independently on the initial sorbate concentration used. The first stage is characterized by a rapid uptake that occurs during the first hours of contact, and is followed by others, characterized by considerable lower uptakes of $\mathrm{Hg}^{2+}$. The equilibrium was attained after a contact period of more than 96 hours, and the initial concentration of $\mathrm{Hg}^{2+}$, had a little effect on the contact time needed to reach the equilibrium.

The removal of $\mathrm{Hg}^{2+}$ by rice husk was calculated for different periods of contact (i.e. $6 \mathrm{~h}, 48 \mathrm{~h}$ and at the equilibrium) and expressed as a percentage and as the concentration of $\mathrm{Hg}^{2+}$ in solution $\left(C_{\mathrm{sol} \mathrm{Hg}}{ }^{2+}, \mu \mathrm{g} \mathrm{L}^{-1}\right)$, (Fig. $3)$. The results show that mercury can be efficiently remove by rice husk, and after a period of contact of only 6 hour, removal values of $66 \%$ and $72 \%$ can be obtained for an initial $\mathrm{Hg}^{2+}$ concentration of $50 \mu \mathrm{g} \mathrm{L}^{-1}$ and $500 \mu \mathrm{g}$ $\mathrm{L}^{-1}$, respectively. Higher percentages of removal can be achieved for longer periods of contact, and at the equilibrium ( $>96 \mathrm{~h}$ ), the values obtained were $82 \%$ for $C_{0}$ $\mathrm{Hg}^{2+}$ of $50 \mu \mathrm{g} \mathrm{L}^{-1}$ and $92 \%$ for a $C_{0 \mathrm{Hg}}{ }^{2+}$ of $500 \mu \mathrm{g} \mathrm{L}^{-1}$. The higher removal percentages obtained for a higher initial sorbate concentration, can be explained by the fact that the initial concentration provides an essential driving force to overcome all mass-transfer resistance of sorbate between the aqueous and solid phases (Ahmaruzzaman and Gupta, 2011).

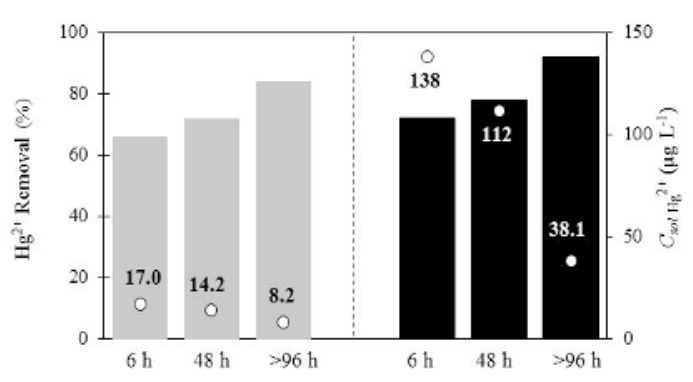

Fig.3. Removal of $\mathrm{Hg}^{2+}$, expressed as: \% (bars) and $C_{\text {sol }}$ $\mathrm{Hg}^{2+}(\mathrm{O})$, for a period of contact of 6,48 and $>96$ hours (situation of equilibrium). Experimental conditions used: $50 \mu \mathrm{g} \mathrm{L}^{-1}$ (grey bars) and $500 \mu \mathrm{g} \mathrm{L}^{-1}$ (black bars); sorbent dose of $0.50 \mathrm{~g} \mathrm{~L}^{-1}$.

Regarding the concentration of $\mathrm{Hg}^{2+}$ in solution, the values obtained after a period of contact of 6 and 48 hours varied between 17 and $14 \mu \mathrm{g} \mathrm{L}^{-1}$, for an initial $\mathrm{Hg}^{2+}$ concentration of $50 \mu \mathrm{g} \mathrm{L}^{-1}$, and between 138 and $112 \mu \mathrm{g}$ $\mathrm{L}^{-1}$, for an initial $\mathrm{Hg}^{2+}$ concentration of $500 \mu \mathrm{g} \mathrm{L}^{-1}$. To reduce the concentration of $\mathrm{Hg}^{2+}$ in solution to the permissible levels for mercury in waters according to the Portuguese legislation, longer contact times are required. In a situation of equilibrium, the one corresponding to periods of contact longer than 96 hours, the concentration of $\mathrm{Hg}^{2+}$ that remains in solution was $38 \mu \mathrm{g} \mathrm{L}^{-1}$ for an initial $\mathrm{Hg}^{2+}$ concentration of $500 \mu \mathrm{g} \mathrm{L}^{-1}$. This equilibrium concentration is lower than $50 \mu \mathrm{g} \mathrm{L}^{-1}$, that represents the actual maximum value for $\mathrm{Hg}$ discharges from industrial sectors (Council Directive 84/156/EEC). Starting with an 
initial $\mathrm{Hg}^{2+}$ concentration of $50 \mu \mathrm{g} \mathrm{L}^{-1}$ the equilibrium concentration was around $8 \mu \mathrm{g} \mathrm{L}^{-1}$, that can be considered a satisfactory result, but not adequate to obtain a clean water with drinking quality $\left(C_{\mathrm{Hg}}{ }^{2+}<1 \mu \mathrm{g} \mathrm{L}^{-1}\right.$ ) (Council Directive 98/83/EC).

\section{Effect of dose of rice husk sorbent}

The sorption capacity of rice husk, for different sorbent doses and for an initial concentration of $\mathrm{Hg}^{2+}$ of $500 \mu \mathrm{g}$ $\mathrm{L}^{-1}$ was evaluated (Fig. 4).

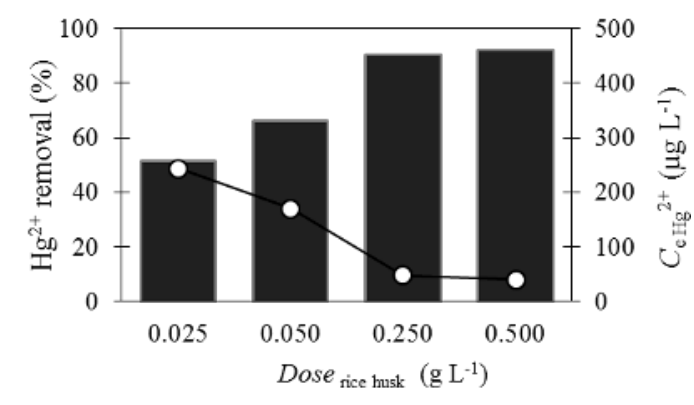

Fig. 4. Removal of $\mathrm{Hg}(\mathrm{II})$ as a function of rice husk dose, expressed as: \% (grey bars) and concentration of $\mathrm{Hg}^{2+}$ at the equilibrium $(\circ)$.

Higher percentages of removal and consequently, lower concentrations of $\mathrm{Hg}^{2+}$ at the equilibrium $\left(C_{e} \mathrm{Hg}^{2+}\right.$, $\mu \mathrm{g} \mathrm{L}^{-1}$ ), are obtained increasing the rice husk dose. Under the experimental conditions used in this work, the minimum $C_{e ~}{ }^{2+}{ }^{2+}$ value was $40 \mu \mathrm{g} \mathrm{L}^{-1}$ (dose of $0.50 \mathrm{~g} \mathrm{~L}^{-1}$ ) and the maximum was $245 \mu \mathrm{g} \mathrm{L}^{-1}$ (dose of $0.025 \mathrm{~g} \mathrm{~L}^{-1}$ ). In percentage values, the removal of $\mathrm{Hg}^{2+}$ increases from $51 \%$ to $92 \%$, with the increase of the sorbent dose from 0.025 to $0.50 \mathrm{~g} \mathrm{~L}^{-1}$. This increase is attributed to the availability of a larger surface area with more sorption sites. For sorbent doses lower than $0.25 \mathrm{~g} \mathrm{~L}^{-1}$, both the \% removal and $C_{e}{ }_{\mathrm{Hg}}{ }^{2+}$ values are strongly affected, and small changes in rice husk dose, give rise to completely different $\mathrm{Hg}^{2+}$ removal and $C_{e} \mathrm{Hg}^{2+}$ values. The sorbent dose is much less relevant for values $\geq 0.25 \mathrm{~g} \mathrm{~L}^{-1}$, and under this circumstances, the removal of $\mathrm{Hg}^{2+}$ remains practically unchanged, reaching a "plateau", that represents the maximal percentage of removal of $\mathrm{Hg}^{2+}$ (around $91 \%$ ) by the rice husk material.

\section{Saturation capacity of the rice husk sorbent}

The saturation capacity of the unmodified rice husk and its subsequent reutilization in further treatments was evaluated in this work. The solution in contact with a rice husk dose of $0.50 \mathrm{~g} \mathrm{~L}^{-1}$ was periodically spiked with $\mathrm{Hg}^{2+}$, whenever the equilibrium was attained.

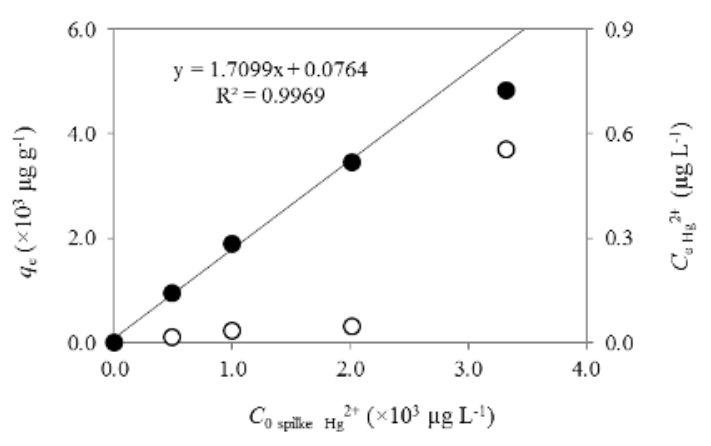

Fig. 5. Amount of $\mathrm{Hg}^{2+}$ sorbed per gram of material at the equilibrium $\left(q_{\mathrm{e}}, \mathrm{mg} \mathrm{g}^{-1} ; q_{\mathrm{e}}=\left(C_{0}-C_{\mathrm{e}}\right) V / m\right)(\bullet)$ and the concentration of $\mathrm{Hg}^{2+}$ remaining in solution at the equilibrium $\left(C_{\mathrm{e} \mathrm{Hg}}{ }^{2+}, \mu \mathrm{g} \mathrm{L}^{-1}\right)(\circ)$, after each spike of $\mathrm{Hg}^{2+}$ $\left(\mathrm{C}_{0 \text { spike Hg}}{ }^{2+}, \mathrm{mg} \mathrm{L}^{-1}\right)$.

The results shows that the linearity $(r=0.997)$ of the $q \mathrm{e} v s \mathrm{C}_{0}$ spike ${ }_{\mathrm{Hg}}{ }^{2+}$ plot is maintained in the interval of $C_{0}$ spike $\mathrm{Hg}^{2+}$ of $[0-2000] \mu \mathrm{g} \mathrm{L}^{-1}$ (Fig. 5), indicating the existence of available binding sites in the rice husk. The deviation from linearity occurs for a $C_{0}$ spike ${ }^{2+}>2000$ $\mu \mathrm{g} \mathrm{L}^{-1}$, suggesting the beginning of the saturation of this sorbent. Regarding the residual (equilibrium) concentration of $\mathrm{Hg}^{2+}\left(C_{\mathrm{e} \mathrm{Hg}^{2+}}\right)$, the values obtained were lower than the $50 \mu \mathrm{g} \mathrm{L}^{-1}$ (maximum value for $\mathrm{Hg}$ discharges from industrial sectors), after spiking the

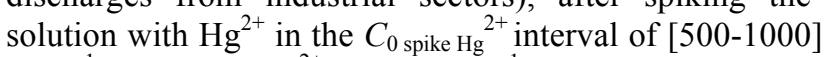

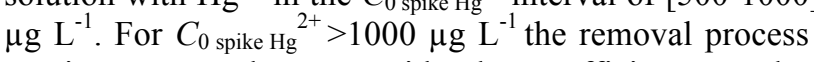
continues to run, however with a lower efficiency. Under these conditions, the values obtained for the $C_{\mathrm{e} \mathrm{Hg}}{ }^{2+}$ were higher than the maximum value for $\mathrm{Hg}$ discharges from industrial sectors, varying between 165 and $580 \mu \mathrm{g} \mathrm{L}^{-1}$.

\section{Conclusion}

The removal of $\mathrm{Hg}^{2+}$ by unmodified rice husk was investigated and for the first time, realistic concentration levels of $\mathrm{Hg}^{2+}$ ( $\mu \mathrm{g} \mathrm{L}^{-1}$ range) were used. As a main conclusion, the unmodified rice husk material proved to be very efficient in the removal of $\mathrm{Hg}^{2+}$ from aqueous solution. If a situation of an accidental spill of $500 \mu \mathrm{g} \mathrm{L}^{-1}$ of $\mathrm{Hg}^{2+}$ occurs, the use of rice husk allow to obtain less than $50 \mu \mathrm{g} \mathrm{L}^{-1}$ of metal in solution, which represents the actual maximum value for $\mathrm{Hg}$ discharges from industrial sectors. Starting from an initial concentration of $\mathrm{Hg}^{2+}$ of $50 \mu \mathrm{g} \mathrm{L}^{-1}$, the concentration in solution after the treatment procedure was around $8 \mu \mathrm{g} \mathrm{L}^{-1}$, that is a satisfactory result, not adequate to obtain a clean water with drinking quality $\left(\mathrm{C}_{\mathrm{Hg}}^{2+}<1 \mu \mathrm{g} \mathrm{L}^{-1}\right)$, but suitable for water recycling within industrial sectors. Additionally, it is possible to reuse the rice husk in additional treatments, and for some experimental conditions, the residual (equilibrium) concentration of $\mathrm{Hg}^{2+}$ was lower than the maximum value for $\mathrm{Hg}$ discharges from industrial sectors.

\section{Acknowledgements}

Thanks are due to University of Aveiro/CESAM and Fundacão para a Ciência e a Tecnologia (FCT). 
Luciana Rocha acknowledge their Post-doc grants to FCT (SFRH/BPD/47166/2008).

\section{References}

Council Directive $84 / 156 /$ EEC on limit values and quality objectives for mercury discharges by sectors other than the chlor-alkali electrolysis industry.

Council Directive $98 / 83 / \mathrm{EC}$ on the quality of water intended for human consumption.

El-Said AG, Badawy NA, Garamon SE. Adsorption of Cadmium (II) and Mercury (II) onto Natural Adsorbent Rice Husk Ash (RHA) from Aqueous Solutions: Study in Single and Binary System. Journal of American Science 2010; 6:400-409.
Feng Q, Lin Q, Gong F, Sugita S, Shoya M. Adsorption of lead and mercury by rice husk ash. Journal of Colloid and Interface Science 2004; 278:1-8.

Khalid N, Ahmad S, Kiani SN, Ahmed J. Removal of Mercury from Aqueous Solutions by Adsorption to Rice Husks. Separation Science and Technology 1999; 34: 3139-3153.

Srivastava S, Goyal P. Novel Biomaterials: Decontamination of Toxic Metals from Wastewater. Environmental Science and Engineering, Springer 2010.

Tiwari DP, Singh DK, Saksena DN. Hg(II) adsorption from aqueous solutions using rice-husk ash. Journal of Environmental Engineering 1995; 121:479-481. 